\title{
Myocardial bridge in a child without hypertrophic cardiomyopathy: A case report
}

\author{
Shiv Kumar Yadav ${ }^{\mathrm{a}}$, Xue Zhou ${ }^{\mathrm{a}}$, Ling He ${ }^{\mathrm{b}}$, Qi-jian Yia \\ ${ }^{a}$ Heart Center, Children's Hospital of Chongqing Medical University, Chongqing, P. R. China. ${ }^{b}$ Department of Radiology, Children's Hospital of \\ Chongqing Medical University, Chongqing, P. R. China
}

\section{A B S T R A C T}

In children, myocardial bridge is an inborn coronary anomaly and is usually found in the patients with hypertrophic cardiomyopathy or left ventricular hypertrophy. Myocardial bridges were long thought to be a benign anatomical variant, even in patients with obstructive and non-obstructive hypertrophic cardiomyopathy. However some patients suffer from myocardial infarction, arrhythmia and even sudden cardiac death. In the present report, we describe a 7-year-old girl with the manifestation of recurrent precordial discomfort, and subsequently diagnosed as having an isolated myocardial bridge in the distal segment of left anterior descending coronary artery using 64-slice computed tomography coronary angiography.

Access this article online

Website:

http://nepjol.info/index.php/AJMS

DOI: 10.3126/ajms.v6i4.11785

Key words: myocardial bridge, hypertrophic cardiomyopathy, child, 64-slice computed tomography.

\section{INTRODUCTION}

Myocardial bridging occurs when a segment of the coronary artery takes an intramural course. This phenomenon was first mentioned by Reyman ${ }^{1}$ in 1737 , and the artery coursing within the myocardium is called a tunneled artery. It is characterized by systolic compression of the tunneled segment, which remains clinically silent in the vast majority of cases. However, some patients had suffered from myocardial ischemia and infarction, even sudden cardiac death due to the presence of a myocardial bridge., ${ }^{2,3}$

\section{CASE REPORT}

A 7-year-old girl was admitted to our department with the manifestation of recurrent episodes of precordial discomfort without any premorbidities. The episodes lasted up to 1 minute and accompanied by pallor, sweating, nausea and vomiting. Physical examination revealed normal vital signs (temperature $36.7^{\circ} \mathrm{C}$, pulse rate $92 / \mathrm{m}$ \& respiratory rate $24 / \mathrm{m})$ ) and the cardiac examination revealed a $2 / 6$ grade systolic blowing murmur in the pericordium. The laboratory tests had no any significant finding on admission.
The electrocardiogram on admission showed pathologic $\mathrm{Q}$ waves in V2, V3 leads, with T wave inversion in V1-V4 leads, and no electrocardiographic signs of chamber hypertrophy, ischemia, or a prolonged QTc interval. During hospitalization, we recordedthe electrocardiogram of a witnessed episode of precordial discomfort, and the electrocardiogram demonstrated ST segment elevation in the limb leads I and aVL. (Figure 1)

Furthermore the cardiac markers performed during the episode were significantly increased, especially the sensitive troponin I was elevated to $27.012 \mathrm{ug} / \mathrm{L}$ (normal range 0 - $0.06 \mathrm{ug} / \mathrm{L}$ ) Echocardiography revealed normal cardiac \& coronary artery anatomy with normal left heart function, but the left ventricular found enlarged with no regional wall motion abnormality.

The patient had two episodes of precordial discomfort during hospitalization. During the second episode, the patient suffered from cardiogenic shock, acute left heart failure, and was transferred to Intensive Care Unit. The bedside echocardiography showed that the left ventricle was dilated with regional ventricular septum motion abnormality. After 3 days' treatment of assisting 


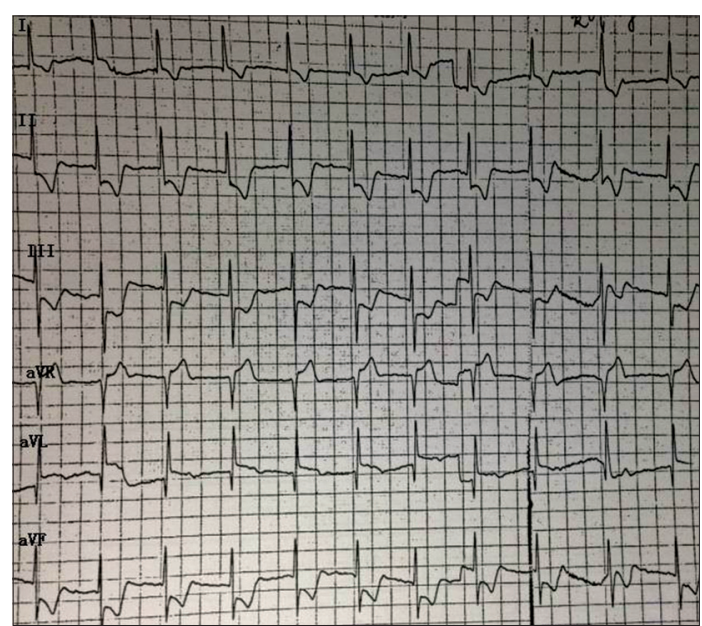

Figure 1: The electrocardiogram manifestation of precordial discomfort onset

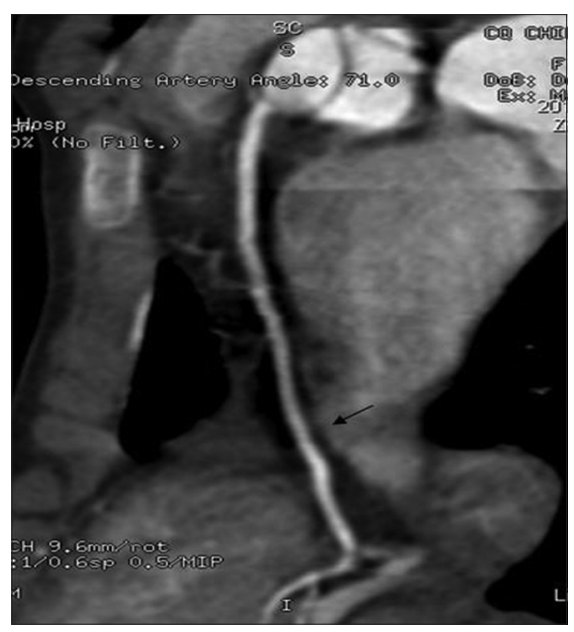

Figure 2: The arrow showed the presence of myocardial bridging located at the distal segment of left anterior descending coronary artery, which was detected by multidetector-row computed tomography coronary angiography

breathing with ventilator, cardiac agents (digoxin), diuretics (furosemide) and some other treatments, the vital signs got stable and she was back to our department. A 24-hour electrocardiographic evaluation showed ventricular ectopic beats, no ST-T segments change, with normal heart rate variability. The multidetector-row computed tomography coronary angiography revealed the presence of myocardial bridging at the distal segment of the left anterior descending coronary artery, with the length of $36.7 \mathrm{~mm}$, and depth of $0.7 \mathrm{~mm}$ (Figure 2). After we made the definitive diagnosis, the patient left the hospital due to some uncertain factors, so she did not get any special treatment.

\section{DISCUSSION}

Myocardial bridge is a band of cardiac muscle overlying the epicardial coronary artery, and the affected coronary termed as tunneled artery. Descriptions of myocardial bridging in children are rare, and its prevalence in the normal pediatric population is unknown. Nearly all reports of myocardial bridge in children occur in association with hypertrophic cardiomyopathy, with a prevalence of $28 \%$ among children with diagnosed hypertrophic cardiomyopathy ${ }^{4}$. There is an ongoing debate whether hypertrophic cardiomyopathy-associated myocardial bridge is an independent risk factor for ischemia and sudden cardiac death in children or simply an indicator of the severity of left ventricular hypertrophy. To our knowledge, the patient in our case, who suffered from cardiogenic shock and acute left heart failure, is the youngest patient with myocardial bridge without hypertrophic cardiomyopathy, and it may confirm the idea that myocardial bridge is a risk factor for serious cardiac events in the form of different clinical symptoms.

Baurassa et. $a 1^{5}$ in 1976 described the angiographic appearance of myocardial bridge, termed a "milking effect", as at least $50 \%$ systolic compression of coronary segment on selective coronary angiography. It is the gold standard for detection of myocardial bridge. Multidetectorrow computed tomography (MDCT) coronary angiography is being increasingly used in the diagnosis of myocardial bridge. Lubarsky et al evaluated the prevalence and characteristics of myocardial bridging in a large series of patients and to assess the relation between atherosclerosis and myocardial bridge $e^{6,7}$ and this might validate MDCT coronary angiography for the diagnosis of myocardial bridge $^{8}$. In our case, the existence of myocardial bridging at the distal segment of the left anterior descending coronary artery was also successfully diagnosed using MDCT coronary angiography. It is of note that the highquality three-dimensional reformations of MDCT coronary angiography enable the assessment of the length, depth and precise location of the tunneled coronary segment ${ }^{9}$, ${ }^{10}$. However, although catheter angiography, intravascular ultrasound (IVUS) and intracoronary Doppler ultrasound (ICD) can be used to identify the morphological and functional features of myocardial bridging, these procedures are invasive. ${ }^{7,11,12}$

Treatment for symptomatic patients with myocardial bridging varies. Medical treatment as a first-line therapy includes nitrates, beta-blockers and calcium antagonists. In patients with severe angina and clinically relevant ischaemia, surgical treatment such as myotomy and coronary artery bypass grafting is considered. Coronary stent implantation may be the treatment of choice for patients whose diseased state is complicated by infarction or recalcitrant ischaemia, in spite of the frequent occurrence of restenosis and major periprocedural complications invasive. . $^{711,14,15}$ 


\section{CONCLUSION}

Accordingly, this case is unique because the patient presented at relative young age with myocardial bridge without hypertrophic cardiomyopathy. We may conclude that myocardial bridge is a risk factor for serious cardiac events in the form of different clinical symptoms, and MDCT coronary angiography, as a useful noninvasive imaging method, can be used in the diagnosis of myocardial bridge. And for the patient with recurrent precordial discomfort, myocardial bridge should be a differential diagnosis (coronary atherosclerosis, Angina \& Myocardial Ischemia) even in the absence of left ventricular hypertrophy. We agree with others ${ }^{13}$ that large multicenter clinical databases are required to identify criteria that justify the link between clinical signs or symptoms and the myocardial bridge as the primary culprit and which move beyond the current empirical approach to the clinical management of this frequent coronary anomaly.

\section{ACKNOWLWDGMENT}

Dr. Chen Xin made a contribution to the coronary artery three-dimensional reconstruction.

\section{REFERENCES}

1. Reyman HC. Disertatio de vasis cordis propriis. Med Diss Univ Gottingen 1737; 1-32.

2. Duygu J, Zoghi M, Nalbantgil S, Kirilmaz B, Turk U, Ozerkan $\mathrm{F}$, et al. Myocardial bridge: A bridge to atherosclerosis. Anadolu Kardiyol Derg 2007; 7:12-16.

3. Rozenberg VD and Nepomnyashchikh LM. Pathomorphology of myocardial bridges and their role in the pathogenesis of coronary disease. Bull Exp Biol Med 2002; 134:593-596.
4. Yetman AT, McCrindle BW, MacDonald C, Freedom RM and Gow R. Myocardial bridging in children with hypertrophic cardiomyopathy: a risk factor for sudden death. N Engl Med 1998;339:1201-1209.

5. Bourassa MG, Butriaru A, Lesperance $\mathrm{J}$ and Tardif JC. Symptomatic myocardial bridges: overview of ischemic mechanism and current diagnostic and treatment strategies. JACC 2003; 41: 351-359.

6. Kramer JR, Kitazume H, Proudfit WL and Sones FM. Clinical significance of isolated coronary bridges: benign and frequent condition involving the left anterior descending artery. Am Heart J 1982; 103:283-288.

7. Möhlenkamp S, Hort W, Junbo $G$ and Raimund E. Update on Myocardial Bridging. Circulation 2002; 106:2616-2622.

8. Lubarsky L, Gupta MP and Hecht HS. Evaluation of myocardial bridging of the left anterior descending coronary artery by 64-slice multidetector computed tomographic angiography. Am J Cardiol 2007; 100:1081-1082.

9. Amoroso G, Battolla L, Gemignani C, Panconi M, Petronio AS and Rondine P. Myocardial bridging on left anterior descending coronary artery evaluated by multidetector computed tomography. Int J Cardiol 2004; 95:335-337.

10. Goitein $\mathrm{O}$ and Lacomis JM. Myocardial bridging: noninvasive diagnosis with multidetector CT. J Comput Assist Tomogr 2005; 29:238-240.

11. Alegria JR, Herrmann J, Holmes DR Jr, Lerman A and Rihal CS. Myocardial bridging. Eur Heart J 2005; 26:1159-1168.

12. Ge J, Jeremias A, Rupp A, Abels M, Baurngart D and Liu F. New signs characteristic of myocardial bridging demonstrated by intracoronary ultrasound and Doppler. Eur Heart J 1999; 20:1707-1716.

13. Angelini $P$, Velasco JA and Flamm S. Coronary anomalies. Incidence, pathophysiology, and clinical relevance. Circulation 2002;105: 2449-2454.

14. Berry JF, von Mering GO, Schmalfuss C, Hill JA and Kerensk RA. Systolic compression of the left anterior descending coronary artery: a case series, review of the literature, and therapeutic options including stenting. Catheter Cardiovasc Interv 2002; 56:58-63.

15. $\mathrm{Ng} \mathrm{E}$, Jilaihawi $\mathrm{H}$ and Gershlick $\mathrm{AH}$. Symptomatic myocardial bridging- a niche indication for drug-eluting stents? Int J Cardiol 2005;99:463-464.

\footnotetext{
Authors Contribution:

SK Yadav - Designed the study, collected the laboratory data, analysed the data, drafted the manuscript \& reviewed the manuscript; Xue Zhou - Contributed to study design, study the laboratory tests; Ling He - Reviewed the manuscript; Qi-jian Yi - Edited and reviewed the manuscript.
}

Source of Support: Nil, Conflict of Interest: None declared. 